\title{
A task for laser cutting of lamellae with TruLaser 1030
}

\author{
Lyubomir Lazov, Hristina Deneva, Pavels Narica \\ Rezeknes Augstskola, Faculty of Engineering, Institute of Regional Studies (REGI), \\ Address: Atbrivosanas aleja 90, Rezekne, LV-4601, Latvia.
}

\begin{abstract}
The growing development of manufacturing, automotive, aerospace and other sectors in the industry generates the necessity to continuously expanding on modifications of electrical machinery and equipments which are used in them, as well as to improve their performance and reliability. The report presents some results from a study to the process of laser cutting through melting on lamellae for rotor and stator packages by using the laser system TruLaser 1030. Some functional dependencies are offered between physical quantities describing the cutting process by melting and technological parameters aimed providing the quality requirements. With a software TruTops to optimize the cutting out are shown the results of studies to determine the technological working time for cutting of a concrete stator lamella.
\end{abstract}

Keywords: laser technology, laser cutting, electrical steel.

\section{INTRODUCTION}

To contemporary production of new and special motors in small series for modern electric cars stay a task to find a new technological solution for cutting of lamellae by Si-sheet metal for stator and rotor packages (fig. 1) [1]. Requirements are: the information by the designer quickly and flexibly to be carries over to the production equipment with which is created and tested new samples.

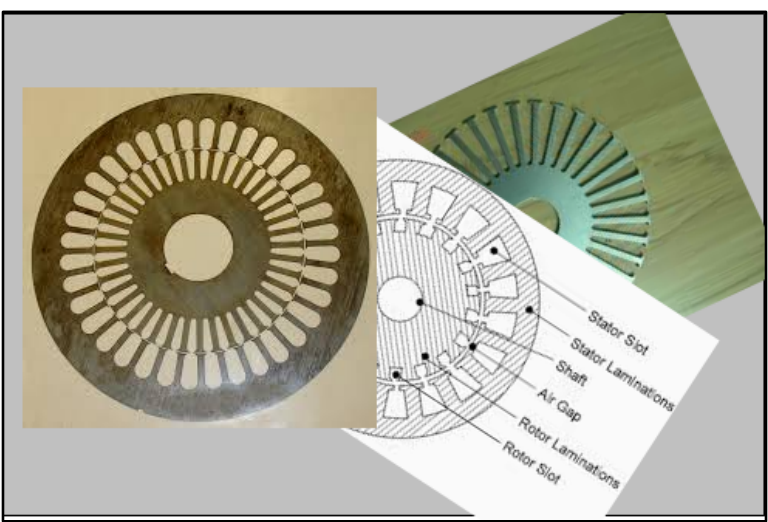

Fig. 1. Lamellae with different geometry

Such possibility provides the laser technology for contour cutting. Extensive specific studies are necessary to make for the deployment of such innovative task. In recent years, a new generation (disk and fiber) lasers appeared [2,3,4]. Laser technique and technology are priority aspects in the industrial production of the 21 st century due to many unique and specific features that these lasers have. They are very efficient for solving the tasks, as well as they provide high performance and flexibility of the cutting process.

Advantages [5] offered by the innovative laser technology for cutting of sheet material in the automotive industry, are:

- very high reliability;

- there is no tool wear - no mechanical action of the process;

- high speed;

- flexibility and changeovers;

- processing of lamellae with complex configuration because of the possibility of the laser radiation to transported by fiber and finely to focus in small work spot;

- a rapid implementation at new constructive solutions, shortening the time of execution (from creating a new drawing to cutting of lamella with new sizes and shapes) ; there is no necessity of production a new punching tool, as it stands in conventional technology;

- reducing the tooling costs;

- reducing the setup times of the technological system;

- lower production costs and higher productivity;

high accuracy of the obtained dimensions;

good quality (no burrs, a small HAZ, etc.). 
Laser technological process is due to the thermal effect of electromagnetic laser energy absorbed from the surface of the material. As indicators for quality to substance treatment are presented in the functional dependence from: the laser parameters (power density, pulse repetition rate, etc.), the parameters of the process (speed of displacement to the laser radiation; physical and chemically properties of the material [5].

\section{CHOICE OF APPROPRIATE LASER SYSTEM}

A suitable choice of laser source is necessary to make at solving any particular task. As for each specific cutting process must be noted:

- characteristics of the laser system (power P of laser radiation, cutting speed $\mathrm{v}$, wavelength $\lambda$, operation mode of the laser source, focal length $f$ of focusing system, type and pressure $p$ of the gas, shape and diameter of gas nozzle $\mathrm{dG}$, etc.);

- specifics of interaction of laser radiation with the substance (a choice of an appropriate method for cutting - by melting and/or evaporation).

For example, the parameters of the laser radiation have to:

- be stable through the entire time of the treatment process;

- correspond at selected method used in the technological process, as well as at the kind and composition of the material, its thickness, the surface quality and the complexity of the contour;

- be able to manage and follow during the work.

It is a matter of fact that the choice of a suitable laser system for each concrete technological process is a complex issue.

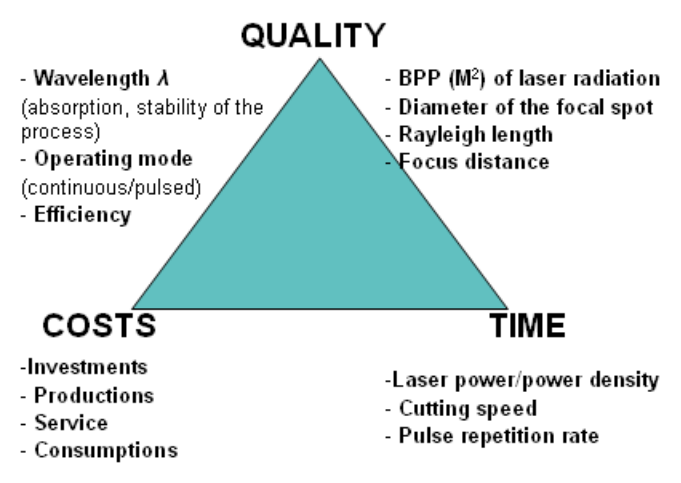

Fig. 2. Important considerations that should be taken into report the choice of laser system for cutting of lamellae

Along with a number of technological factors that should be taken into account, it is necessary to be analyzed and economical ones too (fig. 2):

- investment and production costs;

- efficiency and productivity, etc.

Eventually, the quality of production and its economical efficiency are determined by the correct and optimal selection of these factors and considerations that should be well noted and analyzed.

The aim of the present study is:

1. Conducting of experimental studies in order to give working intervals of the basic technological parameters for the qualitative cutting of lamellae with technological system TruLaser 1030 and disk laser TruDisk 2001 its wavelength is $\lambda=1,03 \mu \mathrm{m}$ and power $P$ up to $2000 \mathrm{~W}$.

2. Cutting of a specific lamella on a sheet material of electric metal steel with TruTops program under real conditions.

\section{METHODS}

In practice, dependent on the laser type, kind of the materials and the requirements of the production itself, there are well known four methods of laser cutting.

They are different both, in the essence and the character of the ongoing physical process, as well as in their capabilities and specific purpose.

\section{Sublimation laser cutting}

Removing the material from the lamella by laser cutting through sublimation is performed by direct evaporation of the substance from the area of impact [6]. Higher power densities are required - about $\left(10^{11}\right.$ $\div 10^{12}$ ) W/ $/ \mathrm{m}^{2}$, in order to realize this cutting process. Basically high power fiber lasers are used. In a single scan of the laser beam along the contour depth of cut in the material is several tens of micrometers.

Several scans along the same contour should be done to realize this method when cutting thicker materials. Although in our case the task is cutting of lamellas with thickness $0,35 \mathrm{~mm}$ and $0,50 \mathrm{~mm}$, this method is not preferred - the results are in good quality, but the cost of technological equipment is quite high as compared with that of disk lasers.

\section{Oxygen laser cutting}

In this cutting method simultaneously with the laser radiation, oxygen is served in the treatment zone through a nozzle $[7,8]$.

There occurs an exothermic reaction of combustion with the release of a large amount of heat, as opposed to the previous method. Heat energy and the energy of laser radiation assisted melting of the material and ultimately accelerated the cutting process, so it is used for the processing of significantly thicker steel sheets. That allows passing the method of oxygen laser cutting with lower power densities (about $10^{9} \mathrm{~W} / \mathrm{m}^{2}$ ). Disadvantages of the method: treatment zone and HAZ are considerably larger comparing to conventional methods. And in the case of the task the method is also unsuitable. 


\section{Laser cutting with water jet}

The specificity of the method is that the laser beam enters along the axis of a thin water jet into the treatment area [9]. In the water jet the beam has total internal reflection as in a fiber. Subsidiary reagent is no added in the processing zone as it could lead to objectionable impacts on the surface treatment of the material - the electrical steel. An additional specialized aggregate needs to be included in order to provide a water pressure up to 500 bar and a flow rate $\mathrm{V}=(5 \div 75) \mathrm{ml} / \mathrm{min}$.

\section{Laser cutting by melting}

In laser cutting by melting in the processing area are reached temperatures higher than the melting temperature $\mathrm{T} \geq \mathrm{Tm}$ of a given material.

The formed melt is discharged from the cutting zone as the influence of steam raising pressure and the gaseous stream - for example nitrogen gas under pressure up to 24 bar [10]. In our experiments the technological system TruLaser 1030 with a built-in disc laser TruDisk 2001 provides output power up to $2000 \mathrm{~W}$ sufficient to realize the laser cutting process by melting. Technological parameters and characteristics of the system are referred to in our previous publications $\lceil 11,12\rceil$.

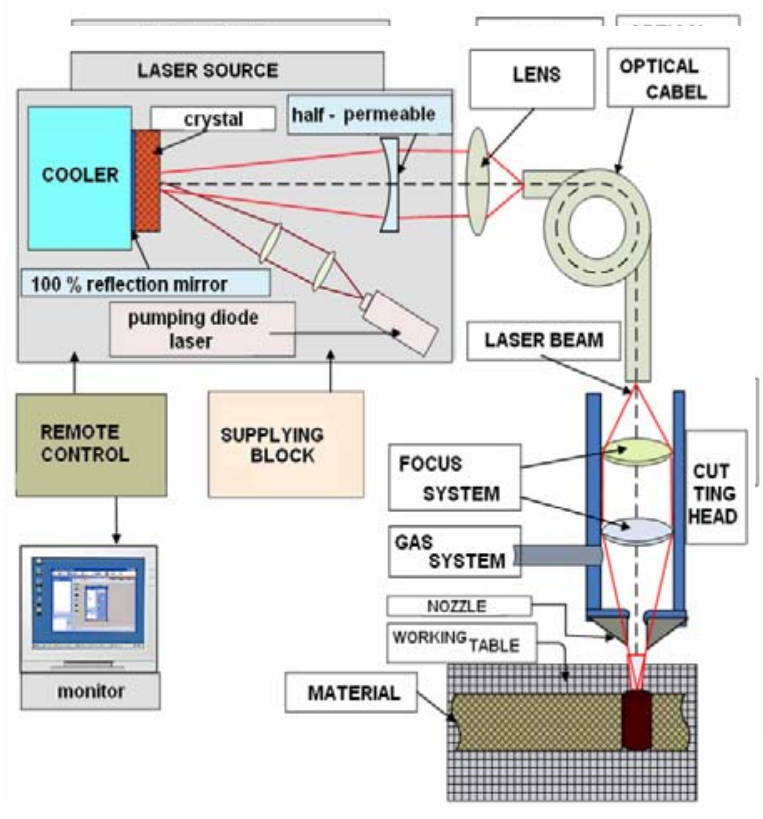

Fig. 3. Principle schema for a laser cutting system

A principle schema for a technological laser system is shown on fig. 3. In it are included the following basic modules:

- laser source TruDisk 2001 of Trumpf company [];

- $\quad$ supply block (26 kVA); remote system; cooler system;

- working table;

- cutting head for moving along $\mathrm{x}, \mathrm{y}$ and $\mathrm{z}$ axis;
- an optical cable for laser beam transporting to the working table;

- focusing system;

- auxiliary gas supply system - nitrogen.

\section{RESULTS AND DISCUSSION}

According to the chosen method, experiments to determine the optimal operating ranges of technological parameters $(P, v, \Delta f$ and $p)$ are carried out as well as analyze their affects on the width $b$ and the cutting quality on samples from electrical steel sheet M250-35A and M530-50A [13, 14].

An essential part of the experiments was oriented to study the impact of the technological parameters (laser power $P$, cutting speed $v$ and gas pressure $p$ ) on $\alpha-$ the angle of divergence on the wall of the cut (fig. 4).

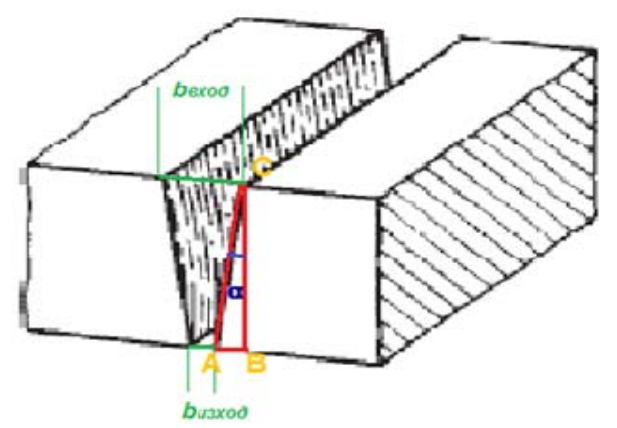

Fig. 4. An angle $\alpha$ defining deviation from parallelisms of the walls through cutting

Changing the power $P$ of laser radiation in the range of $400 \mathrm{~W}$ to $2000 \mathrm{~W}$ at the cutting speed $v=14$ $\mathrm{m} / \mathrm{min}$ on samples of steel sheet with $0,35 \mathrm{~mm}$ thickness leads to change $\Delta \alpha \sim 1,4^{\circ}$ (fig. 5).

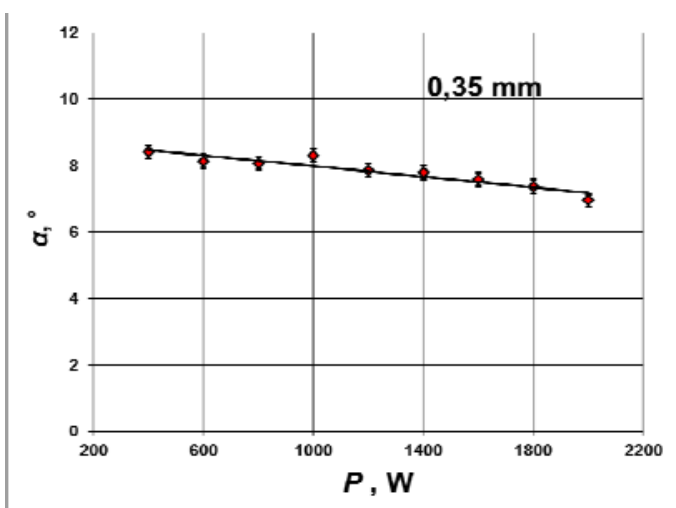

Fig. 5. A chart of dependence $\alpha=\alpha(P)$ at cutting speed $v=14$ $\mathrm{m} / \mathrm{min}$ on samples of M250-35A

Similar graphs of the relation $\alpha=\alpha(P)$ were obtained when cutting specimens M530-50A at speeds $v=(4,8,20) \mathrm{m} / \mathrm{min}$.

To study the relationship $\alpha=\alpha(v)$ the cutting speed is varied in the range $v=(20 \pm 60) \mathrm{m} / \mathrm{min}$, 
respectively at constant power $P=(500,1000,2000)$ $\mathrm{W}$ and pressure $\mathrm{p}$ of the working gas.

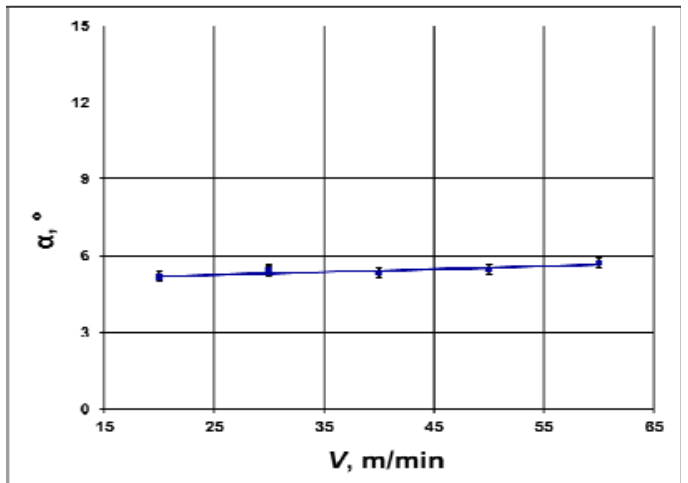

Fig. 6. A graph of experimental dependence $\alpha=\alpha(v)$ for samples of M530-50A at power $P=2000 \mathrm{~W}$

In the studied diapason of speeds the alteration of inclination angle $\alpha$ is very small $\Delta \alpha=0,5^{\circ}$ (fig.6).

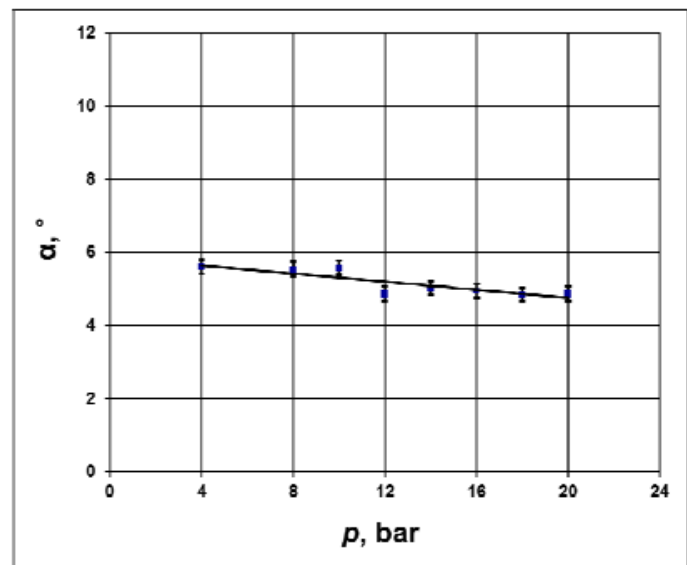

Fig. 7. A graph of experimental relationship $\alpha=\alpha(p)$ when cutting the samples of M530-50A; the power $P=2000 \mathrm{~W}$ and speed $v=50$ $\mathrm{m} / \mathrm{min}$ are constant

The pressure of auxiliary gas-nitrogen is varied in the range $p=(4 \div 20)$ bar with step $\Delta p=2$ bar when studying the dependence $\alpha=\alpha(p)$, in the set of experiments (fig. 7). The obtained results indicate that in the interval from 4 bar to 20 bar as the variable $\Delta \alpha$ is $\sim 1^{\circ}$ for samples with thickness $0,35 \mathrm{~mm}$ and 0,50 $\mathrm{mm}$.

The relationships $b=b(P)$ and $b=b(v)$ for sheet electrical steel M250-35A and M530-50A, are studied in a series of experiments with a special developed methodology. Results are described in detail at our papers $[11,12]$. Analysis shows that the amendment of power $P$ and speed $v$ does not substantially alter the geometry of the cut (the width $b$ of upper and lower surface of the lamella).

For example: The rapidity, with which is being amended width of the cut as the entrance $\Delta b_{\text {enter }}$ and the exit $\Delta b_{\text {exit }}$ in function of power $P=(400 \div 2000)$
$\mathrm{W}$, has many small values, respectively: at the entrance $\Delta b_{\text {enter }} / \Delta P=0,0081 \mu \mathrm{m} / \mathrm{W}$; at the exit $\Delta b_{\text {exit }}$ $/ \Delta P=0,0061 \mu \mathrm{m} / \mathrm{W}$ (fig. 8 ).

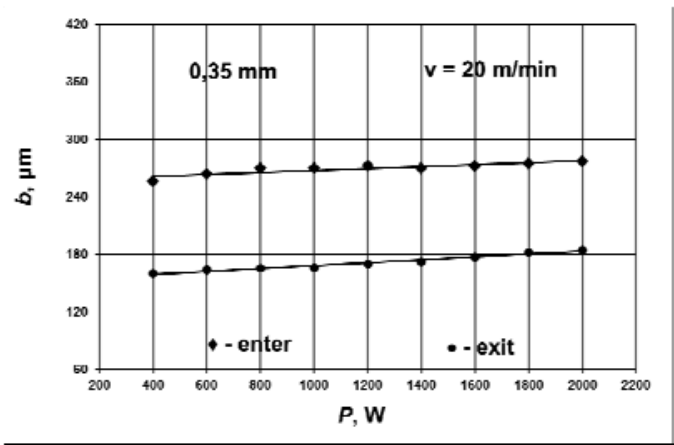

Fig.8. Experimental dependences $b_{\text {enter }}=b_{\text {enter }}(P)$ and $b_{\text {exit }}=b_{\text {exit }}(P)$ at cutting with speed $v=20 \mathrm{~m} / \mathrm{min}$

It is not established significant change of the cutting width $b$ on the entrance and exit when altered the cutting speed $v$ in the range $(20 \div 60) \mathrm{m} / \mathrm{min}$. Average values of cutting width in the studied range of speeds are as follows: M250-35A $-b_{\text {enter }}=(262 \pm 5) \mu \mathrm{m} ; b_{\text {exit }}$ $=(173 \pm 5) \mu \mathrm{m} ;$;a M530-50A $-b_{\text {enter }}=(273 \pm 5) \mu \mathrm{m}$; $b_{\text {exit }}=(168 \pm 5) \mu \mathrm{m}$ (fig. 9).

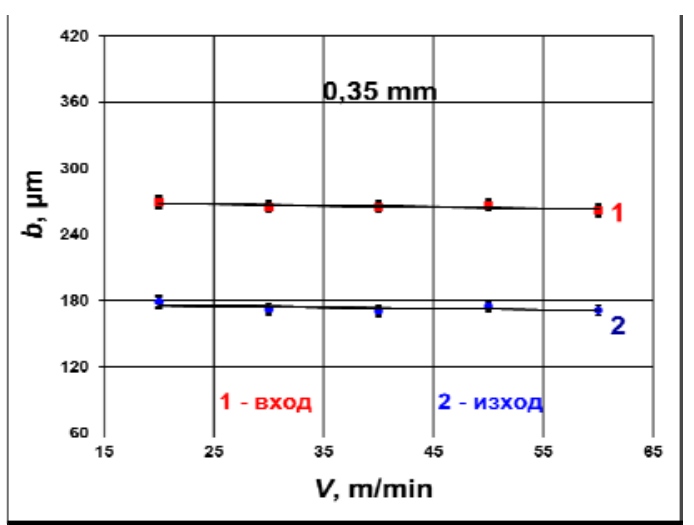

Fig. 9 Graphics of experimental relationships $b_{\text {enter }}=b_{\text {enter }}(v)$ and $b_{\text {exit }}=b_{\text {exit }}(v)$ at constant power $P=1000 \mathrm{~W}$

Cutting quality in studied experiment series are evaluated by using optic observations of the treatment areas.

Operating intervals for the studied technological parameters $P$ and $v$ are defined when cutting of lamellas with good quality:

- Laser power $P=(1000 \mathrm{~W} \div 1400 \mathrm{~W})$ at constant speed $v=20 \mathrm{~m} / \mathrm{min}$ (fig. 10);

- Cutting speed $v=(20 \div 30) \mathrm{m} / \mathrm{min}$ and power $P$ $=1000 \mathrm{~W}$; as well as $v=(20 \div 50) \mathrm{m} / \mathrm{min}$ and power $P=2000 \mathrm{~W}$ (fig. 11). 


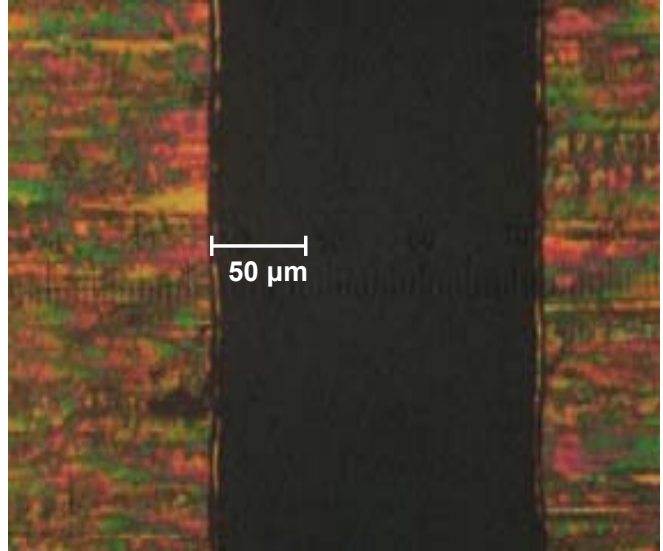

Fig. 10. A cutting section at $P=1200 \mathrm{~W}$ and $v=20 \mathrm{~m} / \mathrm{min}$ on samples of width $0,50 \mathrm{~mm}$

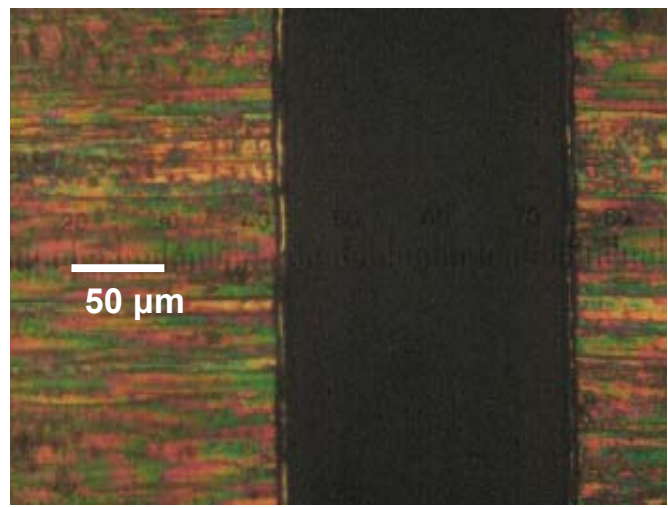

Fig. 11 A section of cut at $P=1000 \mathrm{~W}$ and $v=20 \mathrm{~m} / \mathrm{min}$ of samples with $0,35 \mathrm{~mm}$

\section{Program control of the process}

An optimization for specific cutting is done by software TruTops when using preliminary engineering theoretical and experimental results in the examination of the cutting g process through melt of stator lamella.

Nowadays the program management of the laser processes has been developing very fast.A software controls the movement of the focal spot on a given path to the working surface, as well as adjusts the power of laser radiation and gas supplies. Measured values are recognized by special sensors that controlled the laser process.

The optimization of the laser power and cutting speed during the laser process is one of the biggest challenges to managing the laser processes. For example the laser power and cutting speed have to decrease when there is a motion on complicated contour. In some cases on complex contours the laser beam must be switched off for a split second and then be switched on again. At that time the cutting head must be moved with high speed over the material surface from a one point to a new position. A set of programs for process control in the laser technological system are created for optimization of the cutting.
Programs automatically calculated the best path on which the laser beam has to move as the sequence of scan individual elements (lamellas) in cutting is given, as well as the starting position for cutting each element. The program should be taken into account these values of speeds that are suitable for cutting of curves and angles. This is a comprehensive strategy which must be well thought out and planned.

Control command module of the technological system consists of three groups with included information data:

A) constructive design - a special design of the lamella is drawn in CAD module which is written in the specific track under GEO format;

Б) parameters of the sheet material - the geometry of sheet material $(4000 \times 1000 \times 0,50)$, its thickness and type, surface condition (in our case the varnish holding is type C), optimization function for cutting (cropping as much as possible details with minimal waste), route (fig. 12), etc.;

B) laser technological parameters of the cutting process: power $P$, W; speed $v, \mathrm{~m} / \mathrm{min}$; focal length $f$, $\mathrm{mm}$; focus position $\Delta f, \mathrm{~mm}$; pressure $p$, bar; auxiliary gas (nitrogen), etc.

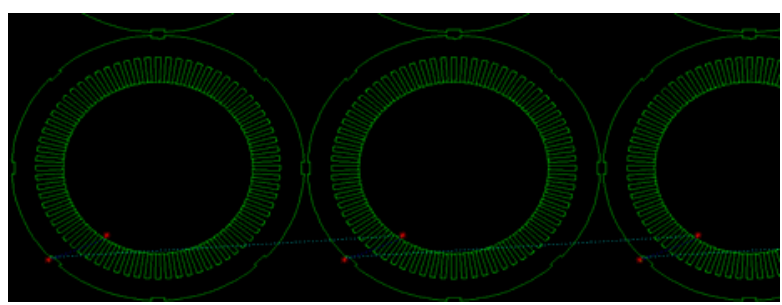

Fig. 12 A cutting route of as stator lamella

$29,02 \mathrm{~min}$ is the measured time for cutting of 36 stator lamellas with smooth and pure edges and 45,24 $\min$ - for 58 lamellas (fig. 13).

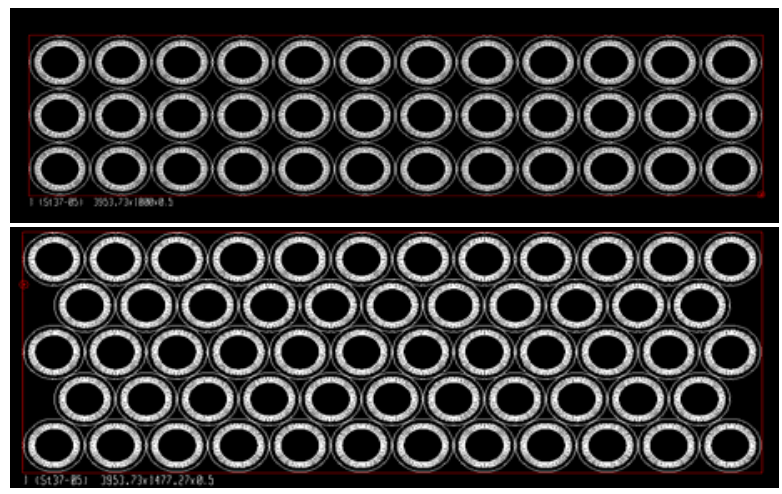

Fig. 13 Optimization cutting of sheet material for 36 and 58 stator lamellae

Based on final results, technological tables are prepared using TruTops software. The technological tables consist of database. They are made for every 
kind of material according to its thickness. The optimal values of laser parameters for the particular technological process as laser power, cutting speed, the type and contour size, focal length, etc., are included in these tables. Any technological table has a separate number and previously is inserted in the machine databases. It could be queried and updated at any time. Only an individual technological table is taken when the process is programmed by the operator. During the process the machine management automatically takes the necessary values from the table.

Using these data, the machine operator can quickly reach the optimal working parameters for the quality cutting of lamellas by electrical steel.

\section{CONCLUSION}

Implementation of the method of laser cutting of thin materials from electrical steel for achieving higher quality in manufacturing process of electric motors is a cause for increasing in the competitiveness of SMSs in Bulgaria and Latvia.

The positive economic and social effect by the introduction of such innovative laser technologies has been connected not only with increasing of the production, but also they created new technological areas, opened new horizons and thereby a large number of jobs; as it leads to improve quality and increase the competitiveness of the products on world markets; intellectualization of the engineering work, resulting in improved working conditions, while increasing the educational level of working staff and ultimately increases the standard of living in countries applying innovative solutions and procedures.

\section{REFERENCES}

[1] G. Pasquarella, Innovation als Antrieb Stator- und Rotorpakete für Elektrische mMaschinen Prototypen und Vorserien., LCD LaserCut AG

[2] T. Himmer, Hochwertig Schneiden mit CO2 und Feiberlasern, Blech Inform 3/2007 pp 50-53

[3] L. Matthias, T. Himmer, Remote-Schneiden mit dem Faserlaser ermöglicht hohe Konturgeschwin-digkeiten, http:/www.maschinenmarkt.vogel.de/themenkanaele/produktio n/trenntechnik/articles/146592/

[4] Fraunhofer-Institut, IWS demonstriert Vorteile beim LaserRemote-Schneiden, Lasys 2008 http://www.blechnet.com/ themen/zulieferungen/articles/105024/

[5] Deneva H., A Study on Laser Cutting Process of Lamellae for Rotor and Stator Packages. Disertation 2014, TU - Gabrovo, pp. 160

[6] Sublimation cutting, Trumpf-laser http://www.us.trumpf.com/ en/products/laser-technology/solutions/applications/lasercutting/sublimation-cutting.html

[7] Schuöcker, D. Handbook of the EuroLaser Academy, Chapman\&Hall, London, 1998, ISBN 0412819201.

[8] Вейко, В. П. Технологические лазеры и лазерное излучение, Санкт-Петербург, ИТМО, 2007, 52c

[9] Mai, T. A., B. Ric, Laser-Microjet: das ideale Werkzeug für Präzisionsmikrobearbeitung.pdf, Oktober 2005,www.synova.ch

[10] LCD LaserCut AG, Laserschneiden und Paketieren von dünnen Blechen bis $0.1 \mathrm{~mm}$ http://www.lcd-lasercut.ch/

[11] Lazov, L., H. Deneva. Investigation of Cutting Width from Laser Power and Velocity. IJETCAS, Issue 4, Vol 1, 2 \& 3, March - May, 2013, ISSN 2279-0047

[12] Lazov, L., H. Deneva. Investigation on the Influence of the Process Parameters Power and Velocity to Laser Cutting of Lamellae. Bulgarian National Conference on Physics, Plovdiv $10-12.10 .2014$ (in the press)

[13] http://www.splav-kharkov.com/main.php

[14] Ленгеров, А., Г. Николчева, П. Даскалов. Изследване на режимите на рязане при обработка на детайли с наварени повърхнини, 10 Международна научно-техническа конференция АМО, 27-29 юни 2010, стр.146. 